\title{
Family Income Gradients in the Health and Health Care Access of US Children
}

\author{
Kandyce Larson $\cdot$ Neal Halfon
}

Published online: 5 June 2009

(C) The Author(s) 2009. This article is published with open access at Springerlink.com

\begin{abstract}
This study sought to examine the shape and magnitude of family income gradients in US children's health, access to care, and use of services. We analyzed cross-sectional data from the 2003 National Survey of Children's Health, a telephone survey of 102,353 parents of children aged 0-17 years. Associations between family income [Below 100\% Federal Poverty Level (FPL), 100-199\% FPL, 200-299\% FPL, 300-399\% FPL, 400\% FPL or Greater] and a set of 32 health and health care indicators were examined using linear polynomial testing and multivariate logistic regression. The percentage of children in better health increased with family income for 15 health outcomes. In multivariate logistic regression models that controlled for health insurance coverage and socio-demographic confounders, odds ratios $>2$ comparing the lowest to the highest income groups were noted for health conditions across both physical and developmental domains (diabetes, headaches, ear infections, learning disabilities, behavior/conduct problems, speech problems).
\end{abstract}

K. Larson $(\bowtie) \cdot$ N. Halfon

UCLA Center for Healthier Children, Families, and

Communities, 10990 Wilshire Boulevard, Suite 900, Los

Angeles, CA 90024, USA

e-mail: kandyce@ucla.edu

K. Larson · N. Halfon

Department of Pediatrics, David Geffen School of Medicine,

UCLA, Los Angeles, CA, USA

\section{N. Halfon}

Department of Health Services, School of Public Health,

UCLA, Los Angeles, CA, USA

N. Halfon

Department of Public Policy, School of Public Affairs,

UCLA, Los Angeles, CA, USA
Parent-reported global child health status, activity limitation, and oral health status showed steeper gradients than specific chronic and acute conditions. Ten measures of health care access and utilization were associated with family income in multivariate logistic regression models. Income gradients are pervasive across many health indicators at an early age. Social and health policy interventions are needed to address the multitude of factors that can affect children's health and initiate disparities in development.

Keywords Income gradients - Health outcomes . Access · Children

$\begin{array}{ll}\text { Abbreviations } \\ \text { OR } & \text { Odds ratio } \\ \text { CI } & \text { Confidence interval } \\ \text { NSCH } & \text { National Survey of Children's Health } \\ \text { UCLA } & \text { University of California Los Angeles } \\ \text { FPL } & \text { Federal poverty level }\end{array}$

\section{Background}

Poverty and material deprivation have long been associated with poorer child health status [1-3]. Many recent studies show that the risk for suboptimal health is not just confined to children from lower social class families, but rather that most risks are graded, and extend across the social class spectrum, resulting in health outcomes that also follow a social gradient [4-6]. Socioeconomic status gradients, with successively higher levels of income, education, or occupational class associated with better children's health have been documented across a range of health indicators including asthma, obesity, acute illness, and injury [7-9]. 
Social class gradients also exist for measures of health care access and utilization [10, 11].

Despite increased attention to SES gradients in child health, there are still several gaps in the knowledge base. Most studies include only a limited number of health or health care access indicators [4, 10, 12], making it difficult to compare the shape, pattern, and magnitude of the gradients across different domains of health and well-being. Much of the health disparities literature focuses on adults more than children, race/ethnicity more than social class, and physical health more than emotional, developmental, or behavioral health [9, 13]. Studies that focus specifically on income differentials in children's health rarely test for linear trends and few include certain specific health conditions such as diabetes, hay fever, or digestive/food allergies [9]. Research in the adult population suggests that some income-health gradients may be steepest at extreme levels of poverty, moderate across middle income levels, and flatten out at very high income levels [14, 15]. Nonetheless, little is known about the exact shape of the family income gradients in children's health across a diverse set of indicators. An understanding of the shape of the gradients in children's health could inform policy decisions about which children might benefit from protective investments on their behalf.

The aim of this study is to examine the associations between family income and children's health, and health care access and utilization using a nationally representative survey of 102,353 parents of children ages $0-17$ years. The National Survey of Children's Health is an ideal data source for an investigation of income gradients in children's health due to the large sample size and comprehensive health assessment. In line with recent definitions of child health, the study incorporates indicators of functional capacity across multiple different domains [13], including physical health, oral health, and emotional, developmental, behavioral health as well as diverse indicators of medical and dental service access and utilization. The study examines whether health improves in a linear fashion with family income, and whether these associations persist in multivariate regression models.

\section{Methods}

Sample

The National Survey of Children's Health (NSCH) was conducted in 2003-2004 by the National Center for Health Statistics as a module of the State and Local Area Integrated Telephone Survey. The survey addresses multiple aspects of children's health and development, access to health care, and use of medical and oral health services. The NSCH used a stratified random-digit-dial sampling design to achieve a nationally representative sample of 102,353 parents of children $0-17$ years of age. One child was randomly selected from all children in each participating household to be the subject of the survey and a detailed telephone interview was conducted with the parent or guardian who knew the most about the child's health and health care experiences. Interviews of approximately 30 min were conducted in English and Spanish. The overall weighted response rate was $55.3 \%$.

The sample for this study is restricted to include only those individuals with non-missing data on the household income measure and all study covariates. This produces a possible sample size of 90,620 for the child health outcome measures and a possible sample size of 90,601 for the health care access and utilization measures. A total of 9,414 respondents did not provide information on household income. Children with missing income data were more likely to be black or Hispanic and to reside in singleparent households. There is some variability in the final study sample for each different health and access/utilization measure due to missing data on the outcome and because certain measures were not relevant and/or not asked for infants or very young children. Most health measures were asked of all children ages $0-17$, except oral health status, unmet dental need, use of dental services (13 months to 17 years); height/weight, vision/hearing, ADHD, behavior/conduct problems, depression/anxiety (2-17 years); severe headaches, ear infections, social/ emotional problems, learning disabilities, and speech problems (3-17 years). The sample never dipped below 70,688 , except for asthma severity/asthma hospitalization (excludes those without asthma), and problem with specialist referral (excludes those without regular provider and no indicated need).

To produce population-based estimates, data records for each interview were assigned a sampling weight. $\mathrm{NSCH}$ sampling weights adjust for differential selection probabilities due to stratification by geographic area and clustering of children within households, multiple telephone lines within a household, and various forms of nonresponse including post-stratification to adjust weights to match population control totals on key demographic variables obtained from Census Bureau data. Further details on the design and operation of $\mathrm{NSCH}$ are reported elsewhere [16]. This study was granted exempt status by the UCLA Institutional Review Board.

Measures

\section{Income}

Parents reported the total combined family income from all sources (e.g., salary and wages, retirement, unemployment, 
public assistance, interest and dividends, etc.) in the calendar year prior to the survey. Respondents could either give an exact dollar amount or report an income range from a series of detailed categories. Income-to-household size measures were computed by National Center for Health Statistics researchers and then compared with Department of Health and Human Services Federal Poverty Guidelines. The final income variable contains five categories: Below 100\% Federal Poverty Level (FPL), 100-199\% FPL, 200-299\% FPL, 300-399\% FPL, 400\% FPL or Greater.

\section{Child Health Outcomes}

Physical health indicators include three general child health status measures: parent-reported global child health status (good/fair/poor health vs. excellent/very good), presence of any activity limitation, and condition of teeth (good/fair/poor vs. excellent/very good). Weight status of NSCH children was determined from calculations of body mass index (BMI) derived from parentreported child height and weight. Children were considered overweight/obese if their BMI was in the 95th percentile or greater compared with children of the same age and sex. Percentiles were determined using Centers for Disease Control and Prevention growth charts [16]. Other specific health conditions were determined by parent report of whether a doctor or health care professional had ever told them that their child had diabetes; bone, joint, muscle problems; vision/hearing problems; asthma; or whether a doctor or health care professional had told them in the past 12 months that their child had severe headaches, ear infections, respiratory allergy/hay fever, digestive/food allergy, or skin allergy.

Parents were asked if the child had any problems with emotions, concentration, or behavior. Other specific measures of emotional, developmental, behavioral health include parent report of a doctor/professional diagnosis of learning disabilities, autism, ADHD, behavior/conduct problems, depression/anxiety, or speech problems.

\section{Access/Utilization Measures}

The presence of a regular provider was assessed by asking parents if at least one health care provider knows their child's health history and serves as a personal doctor or nurse. Respondents with a regular provider were asked if they ever needed a specialty referral, and if so, if they had any trouble receiving needed services. A dichotomous indicator of difficulty accessing specialist services was constructed by combining responses of big/moderate/small problem versus no problem at all. An indicator of unmet medical need was constructed from three questions that ask parents whether their child had seen a doctor in the past
12 months, whether there was any time the child needed medical care (if they had not seen a doctor), and whether the child received all needed care (if they had seen a doctor). Respondents were coded as having an unmet need if they did not see a doctor for any reason but needed care or if they saw a doctor but did not receive all the care needed. An indicator of unmet dental need was constructed in a similar manner (any unmet need for routine service in the past 12 months versus other). Unmet prescription need was indicated by parent report that the child did not receive all needed prescription medications in the past year vs. received all needed services/no need.

Measures of health care utilization include: no medical visit in the past year, no well-child visit in the past year, no dental visit in the past year, asthma hospitalization (only among those with asthma), any emergency room visit, and use of prescription medications in the past year.

\section{Analysis}

All statistical analyses were performed using STATA (version 9.2; Stata Corp, College Station, TX). Survey estimation procedures were applied and the Taylor-series linearization method adjusted the standard errors for the complex survey design. Because research interest was centered on determining whether health and health care access differences showed a graded relationship with family income, linear polynomial statistical testing was used. A significant linear component indicates a trend of increasing (or decreasing) health across categories of family income. If only the linear trend is significant, then the difference in probability of better health is the same at each successive rung up the five category family income variable. A significant deviation from linearity (e.g., quadratic or cubic trend) indicates an uneven gradient. Multivariate logistic regression models examined associations between family income and child health while controlling for maternal race/ethnicity (white, black, Hispanic, multiracial, other), child age in years, child gender, family structure, number of children in the household, and child health insurance coverage in the past year. These controls and global child health status were included in logistic regression models that predict health care access/utilization. These variables were selected from the Anderson behavioral model of health care access and represent predisposing (e.g., race), enabling (e.g., health insurance), and need factors (e.g., child health status) and have been routinely used in other similar studies [11, 17-19]. Dental insurance and parentreported condition of teeth were substituted in models for dental visit and unmet dental need. Family income of $400 \%$ FPL or greater was used as the reference category in regression models. 


\section{Results}

\section{Family Income Levels of US Children}

Including all NSCH respondents, approximately $18 \%$ of US children ages $0-17$ years were poor at the time of survey and another $23 \%$ were in low-income families. Eighteen percent were below $300 \%$ FPL, $16 \%$ were below $400 \%$ FPL, and $27 \%$ were at or above $400 \%$ FPL.

Family Income Gradients in Children's Health and Development

\section{Bivariate Associations}

The percentage of children in worse health declined with increasing family income for 15 health indicators (Table 1). Consistent linear income gradients were noted for seven of these health outcomes, and eight had gradients that were steeper at the lower end of the income range (e.g., poor vs. low-income) than at the higher end (e.g., 300-399\% FPL vs. $400 \%$ FPL or greater) where health differences began to diminish in magnitude.

In the physical health domain, significant income gradients were noted across three general health status indicators (parent-reported global child health status, activity limitations, global condition of teeth) and a range of specific health conditions (overweight/obesity, vision/hearing problems, asthma prevalence and severity, severe headaches and ear infections). The three allergic disorders had reverse income gradients such that allergy prevalence was higher in the upper family income categories. For example, $17.2 \%$ of children in families at $400 \%$ FPL or greater were reported to have respiratory allergy/hay fever and this figure declined to only $12.8 \%$ of those in poor families. Autism was the only developmental health indicator that showed no association with family income.

\section{Multivariate Associations}

Sizable income differentials in children's physical and emotional, developmental, behavioral health remained in multivariate logistic regression models (Table 2). Each general child health status indicator showed a steep family income gradient. For example, odds of good/fair/ poor parent-reported health relative to $400 \%$ FPL or greater were: $300-399 \%$ FPL (OR: $1.24 ; 95 \%$ CI: 1.09-1.43), 200-299\% FPL (OR: 1.74; CI: 1.54-1.96), 100-199\% FPL (OR: 2.69; CI: 2.41-3.01), and below 100\% FPL (OR: 4.73; CI: 4.18-5.35). Likewise, the odds of activity restriction and parent-reported good/fair/poor condition of teeth increased as family income decreased up to more than three comparing the children in the lowest income families to those in the highest. Although not quite as large in magnitude (except for asthma severity), consistent income inequalities were also noted for all specific health conditions other than allergies. Even though diabetes and bone, joint, muscle problems did not follow a gradient pattern in bivariate trend tests, health differentials were found between the lowest income group and the highest (diabetes OR: 2.71, CI: 1.49-4.94; bone, joint, muscle OR: 1.53, CI: 1.21-1.92). The reverse income gradient for respiratory/hay fever and digestive/food allergy did not remain with controls for confounders, although skin allergy continued to show less prevalence as family income decreased.

In the developmental health domain, steep gradients were noted for certain measures like behavior/conduct problems and learning disabilities, while autism was unrelated to family income. Looking across domains, income disparities in children's physical health appear of comparable magnitude to those in the emotional, developmental, and behavioral domain. For example, odds ratios greater than two comparing the lowest to the highest income groups, were noted for specific health conditions in each (e.g., diabetes, headaches, ear infections, learning disabilities, behavior/conduct problems, speech problems).

\section{Family Income Gradients in Children's Health Care} Access/Utilization

\section{Bivariate Associations}

All health care access and utilization measures had significant associations with family income although trends were not always linear (Table 3). In certain instances individuals in the two lowest or two highest income categories had similar access, potentially reflecting eligibility thresholds for public insurance programs (Medicaid and SCHIP). For example, about $23-25 \%$ of poor and low-income children were uninsured at some time during the past year with a steep decline to only $5-7 \%$ of those in the upper two income categories. The gradient for no well child visit was truncated at the low end of the income distribution, while ER use and no regular provider were less steep at the high end. Substantial income gradients were noted for unmet needs. Lower income children were less likely to be reported as using prescription medications even though there was more indicated need.

\section{Multivariate Associations}

All indicators of health care access and utilization, except asthma hospitalization, were associated with family income in multivariate logistic regression models (Table 4). Unmet 
Table 1 Health status of US children according to family income level

\begin{tabular}{|c|c|c|c|c|c|c|c|c|}
\hline & $\begin{array}{l}\text { Sample } \\
\text { size }(N)^{\text {a }}\end{array}$ & $\begin{array}{l}\text { Below } \\
100 \% \text { FPL }\end{array}$ & $\begin{array}{l}\text { 100-199\% } \\
\text { FPL }\end{array}$ & $\begin{array}{l}200-299 \% \\
\text { FPL }\end{array}$ & $\begin{array}{l}300-399 \% \\
\text { FPL }\end{array}$ & $\begin{array}{l}400 \% \text { FPL } \\
\text { or greater }\end{array}$ & $\begin{array}{l}\text { Linear } \\
\text { trend }^{\mathrm{b}}\end{array}$ & $\begin{array}{l}\text { Deviation } \\
\text { from linearity }\end{array}$ \\
\hline \multicolumn{9}{|l|}{ Physical health } \\
\hline Good/fair/poor health (\%) & 90,601 & 33.0 & 19.0 & 11.3 & 7.8 & 6.2 & $P<.05$ & $P<.05$ \\
\hline Activity limitations (\%) & 90,491 & 9.3 & 6.8 & 4.8 & 4.1 & 3.3 & $P<.05$ & NS \\
\hline Good/fair/poor teeth (\%) & 84,788 & 51.3 & 39.6 & 27.4 & 22.0 & 17.1 & $P<.05$ & $P<.05$ \\
\hline Overweight/obese (\%) & 73,852 & 32.8 & 29.8 & 25.0 & 20.9 & 17.6 & $P<.05$ & NS \\
\hline Diabetes $(\%)$ & 90,564 & 0.4 & 0.3 & 0.3 & 0.4 & 0.2 & NS & - \\
\hline Bone, joint, muscle problems (\%) & 90,532 & 3.8 & 3.4 & 2.8 & 3.0 & 3.2 & NS & - \\
\hline Vision/hearing problems (\%) & 79,796 & 4.0 & 2.9 & 2.6 & 2.2 & 2.3 & $P<.05$ & $P<.05$ \\
\hline Asthma (\%) & 90,443 & 13.8 & 13.0 & 12.4 & 12.2 & 11.3 & $P<.05$ & NS \\
\hline Moderate/severe asthma ${ }^{\mathrm{c}}(\%)$ & 7,653 & 54.2 & 36.6 & 34.5 & 22.5 & 21.3 & $P<.05$ & $P<.05$ \\
\hline Severe headaches $(\%)$ & 75,512 & 8.1 & 6.0 & 4.9 & 5.2 & 4.3 & $P<.05$ & $P<.05$ \\
\hline Ear infections (\%) & 75,502 & 7.5 & 5.4 & 4.8 & 3.9 & 3.5 & $P<.05$ & NS \\
\hline \multicolumn{9}{|l|}{ Allergies } \\
\hline Respiratory/hay fever (\%) & 90,371 & 12.8 & 13.7 & 15.7 & 16.4 & 17.2 & $P<.05$ & NS \\
\hline Digestive/food (\%) & 90,477 & 3.5 & 3.2 & 3.6 & 3.7 & 3.9 & $P<.05$ & NS \\
\hline Skin $(\%)$ & 90,492 & 9.1 & 9.8 & 9.4 & 9.6 & 11.1 & $P<.05$ & NS \\
\hline \multicolumn{9}{|l|}{$\begin{array}{l}\text { Emotional, developmental, } \\
\text { behavioral health }\end{array}$} \\
\hline $\begin{array}{l}\text { Problems with emotions, } \\
\text { concentration, behavior }(\%)\end{array}$ & 75,414 & 24.5 & 21.3 & 17.3 & 14.2 & 13.2 & $P<.05$ & NS \\
\hline Learning disabilities $(\%)$ & 75,426 & 14.8 & 11.0 & 9.4 & 7.4 & 6.8 & $P<.05$ & $P<.05$ \\
\hline Autism (\%) & 90,530 & 0.5 & 0.4 & 0.4 & 0.6 & 0.5 & NS & - \\
\hline $\operatorname{ADHD}(\%)$ & 79,620 & 8.2 & 7.0 & 7.3 & 5.9 & 6.4 & $P<.05$ & $P<.05$ \\
\hline Behavior/conduct problems (\%) & 79,823 & 9.6 & 6.2 & 4.5 & 3.6 & 2.8 & $P<.05$ & $P<.05$ \\
\hline Depression/anxiety (\%) & 79,777 & 5.8 & 4.3 & 3.9 & 3.8 & 3.4 & $P<.05$ & NS \\
\hline Speech problems (\%) & 75,545 & 5.8 & 3.8 & 3.3 & 2.9 & 2.5 & $P<.05$ & NS \\
\hline
\end{tabular}

${ }^{a}$ The sample size $(\mathrm{N})$ is limited to only those individuals with no missing data on the covariates for the logistic regression models. The age range of the sample is 0-17 years, although some questions were not relevant and not asked of infants or very young children. There is variability in sample size across all outcomes due to differences in age and missing data on the outcome variables

${ }^{\mathrm{b}}$ Results from linear polynomial statistical test. A significant linear component indicates a trend of increasing (or decreasing) health across categories of family income. A significant deviation from linearity (quadratic/cubic trend) indicates that the change is not constant across all five categories of family income (e.g., gradient may be steeper at lower end of income distribution)

c Only among those with asthma

needs and no regular provider showed steep income gradients with odds ratios greater than 2.5 comparing the lowest income group to the highest. Poor (OR: 1.34; CI: 1.05-1.71) and low-income children (OR: 1.27; CI: 1.06-1.53) were more likely than those in families at $400 \%$ FPL or greater to have parent reported difficulty accessing specialist care. Use of any medical, well-child, or oral health services declined as family income decreased. For example, the odds of no medical visit in the past year were: 300-399\% FPL (OR: 1.33; CI: 1.17-1.51), 200-299\% FPL (OR: 1.56; CI: 1.38-1.75), 100-199\% FPL (OR: 1.99; CI: 1.76-2.23), and below 100\% FPL (OR: 2.42; CI: 2.10-2.79). Emergency room use was more common for children in lower income families, while use of prescription medications was less common.

\section{Discussion}

Prior research has established consistent social class gradients in adult health that extend across disease categories (e.g., diabetes, cardiovascular disease, lung disease) and across indices of health status and well-being [20-23]. This study reveals that even very early in life, substantial income gradients hold up consistently across a broad range of physical and developmental health measures. Health differences associated with family income were not confined to children in poor vs. non-poor families but rather extended across the income spectrum for most health indicators (although gradients were sometimes less steep at upper income levels). Despite their worse health status, children from lower income families also had health 
Table 2 Multivariate logistic regression with family income predicting health status of US children ${ }^{\text {a }}$

\begin{tabular}{|c|c|c|c|c|c|c|}
\hline & $\begin{array}{l}\text { Sample } \\
\text { size }(\mathrm{N})^{\mathrm{b}}\end{array}$ & $\begin{array}{l}\text { Below 100\% FPL } \\
\text { OR }(95 \% \mathrm{CI})\end{array}$ & $\begin{array}{l}\text { 100-199\%FPL } \\
\text { OR }(95 \% \mathrm{CI})\end{array}$ & $\begin{array}{l}200-299 \% \text { FPL } \\
\text { OR }(95 \% \text { CI })\end{array}$ & $\begin{array}{l}300-399 \% \text { FPL } \\
\text { OR }(95 \% \text { CI })\end{array}$ & $\begin{array}{l}400 \% \mathrm{FPL} \\
\text { or greater } \\
\text { OR }(95 \% \mathrm{CI})\end{array}$ \\
\hline \multicolumn{7}{|l|}{ Physical health } \\
\hline Good/fair/poor health & 90,601 & $4.73(4.18-5.35)$ & $2.69(2.41-3.01)$ & $1.74(1.54-1.96)$ & $1.24(1.09-1.43)$ & - \\
\hline Activity limitations & 90,491 & $3.44(2.88-4.11)$ & $2.27(1.96-2.64)$ & $1.52(1.30-1.78)$ & $1.25(1.05-1.50)$ & - \\
\hline Good/fair/poor teeth & 84,788 & $3.61(3.26-4.00)$ & $2.56(2.35-2.78)$ & $1.68(1.55-1.83)$ & $1.31(1.20-1.44)$ & - \\
\hline Overweight/obese & 73,852 & $1.86(1.65-2.10)$ & $1.83(1.66-2.01)$ & $1.55(1.41-1.62)$ & $1.25(1.14-1.38)$ & - \\
\hline Diabetes & 90,564 & $2.71(1.49-4.94)$ & $1.57(0.90-2.73)$ & $1.74(1.10-2.76)$ & $2.03(1.10-3.76)$ & - \\
\hline Bone, joint, muscle problems & 90,532 & $1.53(1.21-1.92)$ & $1.20(1.00-1.44)$ & $0.91(0.75-1.10)$ & $0.94(0.78-1.15)$ & - \\
\hline Vision/hearing problems & 79,796 & $1.65(1.21-2.25)$ & $1.16(0.89-1.52)$ & $1.09(0.85-1.39)$ & $0.92(0.71-1.19)$ & - \\
\hline Asthma & 90,443 & $1.26(1.11-1.44)$ & $1.18(1.06-1.31)$ & $1.12(1.01-1.25)$ & $1.09(0.97-1.21)$ & - \\
\hline Moderate/severe asthma ${ }^{c}$ & 7,653 & 3.51 (2.64-4.67) & $1.82(1.40-2.36)$ & $1.76(1.35-2.29)$ & $1.02(0.77-1.35)$ & - \\
\hline Severe headaches & 75,512 & $2.02(1.65-2.48)$ & $1.43(1.20-1.69)$ & $1.16(0.98-1.36)$ & $1.21(1.01-1.46)$ & - \\
\hline Ear infections & 75,502 & $2.52(2.06-3.07)$ & $1.71(1.44-2.03)$ & $1.43(1.21-1.69)$ & $1.14(0.94-1.36)$ & - \\
\hline \multicolumn{7}{|l|}{ Allergies } \\
\hline Respiratory/hay fever & 90,371 & $0.90(0.80-1.01)$ & $0.88(0.81-0.97)$ & $0.96(0.88-1.04)$ & $0.98(0.89-1.07)$ & - \\
\hline Digestive/food & 90,477 & $0.94(0.76-1.17)$ & $0.85(0.71-1.03)$ & $0.95(0.80-1.12)$ & $0.97(0.81-1.15)$ & - \\
\hline Skin & 90,492 & $0.75(0.65-0.87)$ & $0.85(0.75-0.95)$ & $0.83(0.75-0.92)$ & $0.86(0.76-0.96)$ & - \\
\hline \multicolumn{7}{|c|}{ Emotional, developmental, behavioral health } \\
\hline $\begin{array}{l}\text { Problems with emotions, } \\
\text { concentration, behavior }\end{array}$ & 75,414 & $2.08(1.83-2.36)$ & $1.72(1.55-1.91)$ & $1.35(1.22-1.49)$ & $1.08(.97-1.20)$ & - \\
\hline Learning disabilities & 75,426 & $2.66(2.26-3.12)$ & $1.78(1.56-2.04)$ & $1.45(1.27-1.65)$ & $1.09(0.95-1.25)$ & - \\
\hline Autism & 90,530 & $1.21(0.69-2.11)$ & $0.98(0.63-1.55)$ & $0.87(0.59-1.28)$ & $1.18(0.78-1.78)$ & - \\
\hline ADHD & 79,620 & $1.82(1.52-2.18)$ & $1.29(1.11-1.50)$ & $1.22(1.06-1.40)$ & $0.91(0.79-1.05)$ & - \\
\hline Behavior/conduct problems & 79,823 & $3.65(3.01-4.44)$ & $2.23(1.88-2.65)$ & $1.58(1.32-1.89)$ & $1.28(1.06-1.54)$ & - \\
\hline Depression/anxiety & 79,777 & $2.00(1.63-2.44)$ & $1.36(1.13-1.64)$ & $1.14(0.96-1.36)$ & $1.10(0.92-1.32)$ & - \\
\hline Speech problems & 75,545 & $2.05(1.59-2.65)$ & 1.36 (1.09-1.70) & $1.24(0.98-1.56)$ & $1.10(0.87-1.39)$ & - \\
\hline
\end{tabular}

${ }^{a}$ Model includes controls for maternal race/ethnicity, child age, child gender, family structure, number of children in the household, and insurance status. Significant values $(P<.05)$ are shown in bold

b The age range of the sample is $0-17$ years, although some questions were not relevant and not asked of infants or very young children. There is variability in sample size across all outcomes due to differences in age and missing data on the outcome variables

c Only among those with asthma

services marked by less continuity (e.g., no regular provider), more unmet needs, and fewer health visits outside of the emergency room. In multivariate models that control for a range of confounders plus health insurance status, striking income disparities in children's health and health care access/utilization persist.

In the physical health domain, significant income gradients were noted across three general health indicators (global child health status, activity limitation, global condition of teeth) and a range of specific health conditions (overweight/obesity, asthma, vision/hearing problems, headaches, and ear infections). Diabetes and bone, joint, muscle problems did not manifest as gradients, although there were health differentials between the rich and the poor. Allergies (respiratory/hay fever, digestive/food, and skin) were the only physical health measures included in this study that did not show associations in the expected direction (and in fact showed gradients in the opposite direction, with those in the highest income category reporting worse health). This finding is consistent with a small number of studies in the US and other Western industrialized countries showing that hay fever and other allergies may be more common for higher SES individuals [24-26]. One possible explanation for the reverse incomeallergy gradient found in this study is that higher social class parents may be more likely to obtain a physician diagnosis of allergic disorder for their children due to better health care access or screening for these conditions. Less educated parents may also not recognize allergies, and classify similar symptom patterns as colds, variations of normal, and not notable as a medical condition. Alternatively, the "hygiene hypothesis" states that a lack of early 
Table 3 Access to health care and utilization of services among US children according to family income level

\begin{tabular}{|c|c|c|c|c|c|c|c|c|}
\hline & $\begin{array}{l}\text { Sample } \\
\text { size }(N)^{\text {a }}\end{array}$ & $\begin{array}{l}\text { Below } 100 \% \\
\text { FPL }\end{array}$ & $\begin{array}{l}\text { 100-199\% } \\
\text { FPL }\end{array}$ & $\begin{array}{l}200-299 \% \\
\text { FPL }\end{array}$ & $\begin{array}{l}300-399 \% \\
\text { FPL }\end{array}$ & $\begin{array}{l}400 \% \text { FPL } \\
\text { or greater }\end{array}$ & $\begin{array}{l}\text { Linear } \\
\text { trend }^{\mathrm{b}}\end{array}$ & $\begin{array}{l}\text { Deviation } \\
\text { from } \\
\text { linearity }^{b}\end{array}$ \\
\hline \multicolumn{9}{|l|}{ Access } \\
\hline Uninsured in the past year $(\%)$ & 90,601 & 25.2 & 22.6 & 13.1 & 7.5 & 4.8 & $P<.05$ & $P<.05$ \\
\hline $\begin{array}{l}\text { No dental insurance at time of } \\
\text { survey }(\%)\end{array}$ & 83,759 & 28.3 & 24.7 & 22.1 & 17.2 & 17.3 & $P<.05$ & $P<.05$ \\
\hline No regular provider $(\%)$ & 90,405 & 31.1 & 20.8 & 13.0 & 9.6 & 7.2 & $P<.05$ & $P<.05$ \\
\hline $\begin{array}{l}\text { Problem with specialist referral }{ }^{c} \\
\quad(\%)\end{array}$ & 19,475 & 31.2 & 27.1 & 21.9 & 21.2 & 19.3 & $P<.05$ & NS \\
\hline Unmet medical care $(\%)$ & 90,332 & 2.8 & 1.8 & 1.1 & 0.5 & 0.3 & $P<.05$ & NS \\
\hline Unmet dental care $(\%)$ & 83,464 & 8.4 & 8.1 & 5.3 & 3.1 & 1.8 & $P<.05$ & $P<.05$ \\
\hline Unmet prescription (\%) & 90,347 & 1.8 & 1.2 & 0.5 & 0.3 & 0.2 & $P<.05$ & NS \\
\hline \multicolumn{9}{|l|}{ Utilization } \\
\hline \multicolumn{9}{|l|}{ No medical visit } \\
\hline $\begin{array}{l}\text { No medical visit in the past } \\
\text { year }(\%)\end{array}$ & 90,413 & 21.0 & 17.6 & 13.2 & 11.2 & 8.3 & $P<.05$ & NS \\
\hline $\begin{array}{l}\text { No well-child visit in the past } \\
\text { year }(\%)\end{array}$ & 89,997 & 27.0 & 25.8 & 23.4 & 20.1 & 15.4 & $P<.05$ & $P<.05$ \\
\hline \multicolumn{9}{|l|}{ No dental visit } \\
\hline $\begin{array}{l}\text { No dental visit in the past year } \\
(\%)\end{array}$ & 83,473 & 30.3 & 26.5 & 20.8 & 16.0 & 15.3 & $P<.05$ & $P<.05$ \\
\hline Hospitalized for asthma ${ }^{\mathrm{d}}(\%)$ & 10,767 & 6.5 & 5.1 & 3.2 & 1.6 & 3.3 & $P<.05$ & $P<.05$ \\
\hline ER use $(\%)$ & 90,362 & 23.9 & 20.3 & 17.5 & 16.2 & 15.8 & $P<.05$ & $P<.05$ \\
\hline $\begin{array}{l}\text { Used a prescription in past year } \\
(\%)\end{array}$ & 70,688 & 44.8 & 45.2 & 48.8 & 51.2 & 53.2 & $P<.05$ & NS \\
\hline Did not use, but needed (\%) & 34,961 & 9.2 & 5.1 & 4.8 & 3.0 & 3.4 & $P<.05$ & $P<.05$ \\
\hline
\end{tabular}

a The sample size $(\mathrm{N})$ is limited to only those individuals with no missing data on the covariates for the logistic regression models. The age range of the sample is $0-17$ years, although some questions were not relevant and not asked of infants or very young children. There is variability in sample size across all outcomes due to differences in age and missing data on the outcome variables

b Results from linear polynomial statistical test. A significant linear component indicates a trend of increasing (or decreasing) access across categories of family income. A significant deviation from linearity (quadratic/cubic trend) indicates that the change is not constant across all five categories of family income (e.g., gradient may be steeper at lower end of income distribution)

${ }^{c}$ Only among children whose providers thought they needed to see a specialist

d Only among those with asthma

childhood exposure to infectious agents and bacteria (which may be more common in higher SES families) increases susceptibility to allergic diseases by modulating immune system development [27].

In the developmental and behavioral health domain, gradients were noted for all health indicators except autism. Autism is known to have a strong genetic link [28, 29] and may be less susceptible to social environmental influences than other disorders like behavior/conduct problems and learning disabilities which showed steep family income gradients in this study. This could also relate to differential screening, as research indicates greater delays in diagnosis of autism for children from disadvantaged social groups and possibly even more misdiagnoses with other common co-morbid disorders like ADHD or adjustment problems [30-32]. Although measurement issues and choice of health indicators complicate cross-domain comparisons, it is noteworthy that income gradients in children's physical health appear of comparable magnitude to emotional, developmental, behavioral health in this comprehensive study. This is contrary to the findings of some studies with multi-dimensional measures of health that have found steeper social class gradients in the psychosocial domain during childhood [6], and highlights the important early influence of family income on general physical well-being and chronic/acute disorders, as well as emotional, developmental, behavioral health. Parent-rated global child health status showed a particularly steep income gradient.

The sub-optimal health and developmental status of children from lower income families would seem to suggest that these are the individuals most in need of attention by the health service system. On the contrary, this study uncovered substantially reduced access to health services 
Table 4 Multivariate logistic regression with family income predicting health care access/utilization among US children ${ }^{\mathrm{a}}$

$$
\begin{array}{llllll}
\text { Sample } & \text { Below 100\% FPL } & \text { 100-199\% FPL } & \text { 200-299\% FPL } & \text { 300-399\% FPL } & \text { 400\% FPL } \\
\text { size }(\mathrm{N})^{\mathrm{b}} & \text { OR }(95 \% \mathrm{CI}) & \text { OR }(95 \% \mathrm{CI}) & \text { OR }(95 \% \mathrm{CI}) & \text { OR (95\% CI) } & \text { or greater }
\end{array}
$$

\begin{tabular}{|c|c|c|c|c|c|c|}
\hline \multicolumn{7}{|l|}{ Access } \\
\hline No regular provider & 90,405 & $3.53(3.12-4.00)$ & $2.37(2.13-2.64)$ & $1.66(1.48-1.87)$ & $1.29(1.14-1.46)$ & - \\
\hline Problem with specialist referral $^{c}$ & 19,475 & $1.34(1.05-1.71)$ & $1.27(1.06-1.53)$ & $1.05(0.89-1.25)$ & $1.08(0.91-1.28)$ & - \\
\hline Unmet medical care & 90,332 & $3.96(2.34-6.68)$ & $2.94(1.93-4.48)$ & $2.45(1.56-3.85)$ & $1.33(0.83-2.14)$ & - \\
\hline Unmet dental care & 83,464 & $2.51(1.96-3.22)$ & $2.94(2.39-3.62)$ & $2.31(1.87-2.85)$ & $1.55(1.18-2.03)$ & - \\
\hline Unmet prescription & 90,347 & $4.67(2.51-8.70)$ & $3.46(2.10-5.70)$ & $1.90(1.08-3.35)$ & $1.37(0.80-2.34)$ & - \\
\hline \multicolumn{7}{|l|}{ Utilization } \\
\hline \multicolumn{7}{|l|}{ No medical visit } \\
\hline No medical visit in the past year & 90,413 & $2.42(2.10-2.79)$ & $1.99(1.76-2.23)$ & $1.56(1.38-1.75)$ & $1.33(1.17-1.51)$ & - \\
\hline No well-child visit in the past year & 89,997 & $2.00(1.79-2.25)$ & $1.82(1.66-1.99)$ & $1.64(1.50-1.79)$ & $1.35(1.23-1.49)$ & - \\
\hline \multicolumn{7}{|l|}{ No dental visit } \\
\hline No dental visit in the past year & 83,473 & $2.33(2.06-2.64)$ & $2.10(1.91-2.31)$ & 1.53 (1.39-1.67) & $1.16(1.05-1.29)$ & - \\
\hline Hospitalized for asthma ${ }^{\mathrm{d}}$ & 10,767 & $0.75(0.40-1.44)$ & $0.81(0.46-1.40)$ & $0.70(0.38-1.30)$ & $0.44(0.23-0.84)$ & - \\
\hline ER use & 90,362 & $1.47(1.32-1.64)$ & $1.30(1.19-1.42)$ & $1.12(1.02-1.22)$ & $1.04(0.95-1.15)$ & - \\
\hline Used a prescription in past year & 70,688 & $0.85(0.76-0.94)$ & $0.84(0.77-0.91)$ & $0.89(0.83-0.96)$ & $0.96(0.89-1.04)$ & - \\
\hline \multicolumn{7}{|c|}{$\begin{array}{l}\text { "Model includes controls for maternal race/ethnicity, child age, child gender, family structure, number of children in the household, child health } \\
\text { status, and health insurance status in the past year. For "unmet dental care" and "no dental visit in the past year," dental insurance and oral } \\
\text { health status were substituted as controls. Significant values }(P<.05) \text { are shown in bold }\end{array}$} \\
\hline
\end{tabular}

for children from lower income families across the full range of health care access and utilization indicators available in NSCH, and these associations largely persisted in multivariate models with controls for confounders. The considerably lower rates of having a continuous health care provider for children in lower income families is disconcerting given the important role that such an individual could play as a long-term developmental advocate for the child [33]. Receiving primary care from the same physician has been associated with more frequent discussions about child health supervision topics and more preventive health visits [34-36]. Sizable income disparities were also noted for unmet health needs (medical, dental, prescription) and use of routine and preventive health services and these disparities remained in models that included controls for health insurance status suggesting that although universal health coverage may be a necessary first step toward achieving equity in children's access to health care, it may not be sufficient to close the large gaps in service between children in low- and high-income families. A multitude of financial and non-financial barriers beyond lack of health insurance coverage may inhibit access and use of health services by lower income families, including insufficient physician availability, health plan coverage limitations, high co-payments, transportation barriers, and time constraints $[37,38]$.

Addressing inequities in children's health care coverage and access to quality health services seems an important component of any strategy to reduce income gradients in children's health, but it is also likely that changes outside the health care system will be necessary [38-42]. In this study, sizable income gradients in children's health and development remained in multivariate models that controlled for health insurance status suggesting that other interventions that address the varied social determinants of children's health (including social-emotional health) may be necessary. This might include macro-level social policy changes to address the upstream determinants of children's health (e.g., income inequality, unemployment, inadequate time for parenting) as well as social, educational, and public health interventions designed to provide a wide variety of supportive services for children and families (e.g., parenting classes, family mental health services, comprehensive early intervention programs) [43]. The notion of a gradient suggests that not only do poor children fare worse than upper class children, but middle class 
children fare worse than upper class children too. Therefore policy strategies might very well combine interventions targeting lower socioeconomic groups, along with more broad-based universal programs needed to optimize the health and developmental trajectories of all children. The US literature has placed a great deal of emphasis on the problem of child poverty and the related policy debate often centers on whether to provide various forms of means-tested poor relief or encourage individual responsibility among the poor. However, by evaluating health differences in relationship to broader social gradients, the somewhat arbitrary distinctions imposed by a specific income level become less salient and policy considerations move from a focus on poverty to that of income inequality and the promotion of social inclusion through the provision of services to enhance health and well being for all children.

This study has several limitations. All measures of children's health and access/utilization were reported by parents and subject to potential reporting bias. Some indicators of children's health were indicated by parent report of a physician diagnosis, meaning that children with worse health care access may have had less opportunity for detection of the condition. The study is cross-sectional and therefore no causal inferences can be made. Children's health conditions could, for example, influence family income levels instead of the reverse. In terms of measuring the shape of the income gradients in children's health, it is important to note that the study was limited to a five-category income variable with an upper limit of $400 \%$ FPL or greater. This means that health indicators that showed consistent linear improvements with family income could still exhibit a trend of declining health improvement beyond $400 \%$ FPL or greater. The study does not address the mechanisms responsible for income differentials in children's health. The strong associations between income and health suggest that income serves as a proxy for a range of different family and environmental factors relevant to children's health.

Available cross-national research shows considerable variability in the magnitude of socioeconomic gradients in human health and development across industrialized nations [21, 44-46]. Some evidence suggests that SES gradients may be less steep in countries that offer more egalitarian health and human development polices such as the provision of adequate family income, adequate time for parenting, and generous supportive services including universal health care coverage [44, 46, 47]. Life course theoretical models posit that the origins of adult social disparities in health can be traced back to the formative childhood years of development [44, 48, 49], and a substantial amount of research suggests that the health risks associated with early social disadvantage carry forward into adulthood and may be compounded across time [50-53]. In this regard, it seems imperative that social and health policy attention be directed at efforts to prevent the development of the substantial and consistent income gradients in children's health found in this study.

Acknowledgments This research was supported in part by funding from the Maternal and Child Health Bureau of the Health Resources and Services Administration Interdisciplinary Maternal and Child Health Training Program (2 T76M600014:11) (Dr. Halfon) and NIHLRP (Dr. Larson). We wish to thank Louba Aaronson and Carolyn Lertzman who assisted with data analysis and manuscript preparation.

Open Access This article is distributed under the terms of the Creative Commons Attribution Noncommercial License which permits any noncommercial use, distribution, and reproduction in any medium, provided the original author(s) and source are credited.

\section{References}

1. Aber, J. L., Bennett, N. G., Conley, D. C., \& Li, J. (1997). The effects of poverty on child health and development. Annual Review of Public Health, 18, 463-483. doi:10.1146/annurev. publhealth.18.1.463.

2. Duncan, G. J., \& Brooks-Gunn, J. (1997). Consequences of growing up poor. New York: Russell Sage Foundation.

3. Halfon, N., \& Newacheck, P. W. (1993). Childhood asthma and poverty: Differential impacts and utilization of health services. Pediatrics, 91(1), 56-61.

4. Chen, E., Martin, A. D., \& Matthews, K. A. (2006). Socioeconomic status and health: Do gradients differ within childhood and adolescence? Social Science and Medicine, 62(9), 2161-2170. doi:10.1016/j.socscimed.2005.08.054.

5. Starfield, B., Riley, A. W., Witt, W. P., \& Robertson, J. (2002). Social class gradients in health during adolescence. Journal of Epidemiology and Community Health, 56(5), 354-361. doi: 10.1136/jech.56.5.354.

6. Starfield, B., Robertson, J., \& Riley, A. W. (2002). Social class gradients and health in childhood. Ambulatory Pediatrics, 2(4), 238-246. doi:10.1367/1539-4409(2002)002<0238:SCGAHI $>2.0 . \mathrm{CO} ; 2$.

7. Chen, E., Hanson, M. D., Paterson, L. Q., Griffin, M. J., Walker, H. A., \& Miller, G. E. (2006). Socioeconomic status and inflammatory processes in childhood asthma: The role of psychological stress. The Journal of Allergy and Clinical Immunology, 117(5), 1014-1020. doi:10.1016/j.jaci.2006.01.036.

8. Chen, E., Martin, A. D., \& Matthews, K. A. (2006). Understanding health disparities: The role of race and socioeconomic status in children's health. American Journal of Public Health, 96(4), 702-708. doi:10.2105/AJPH.2004.048124.

9. Chen, E., Matthews, K. A., \& Boyce, W. T. (2002). Socioeconomic differences in children's health: How and why do these relationships change with age? Psychological Bulletin, 128(2), 295-329. doi:10.1037/0033-2909.128.2.295.

10. Hughes, D. C., Duderstadt, K. G., Soobader, M. P., \& Newacheck, P. W. (2005). Disparities in children's use of oral health services. Public Health Reports, 120(4), 455-462.

11. Newacheck, P. W., Hung, Y. Y., Park, M. J., Brindis, C. D., \& Irwin, C. E., Jr. (2003). Disparities in adolescent health and health care: Does socioeconomic status matter? Health Services Research, 38(5), 1235-1252. doi:10.1111/1475-6773.00174. 
12. Finch, B. K. (2003). Socioeconomic gradients and low birthweight: Empirical and policy considerations. Health Services Research, 38(6 Pt 2), 1819-1841. doi:10.1111/j.1475-6773.2003. 00204.x.

13. National Research Council and Institute of Medicine. Committee on Evaluation of Children's Health. (2004). Children's health, the nation's wealth: Assessing and improving child health. Washington, DC: National Academies Press.

14. Backlund, E., Sorlie, P. D., \& Johnson, N. J. (1996). The shape of the relationship between income and mortality in the United States. Evidence from the National Longitudinal Mortality Study. Annals of Epidemiology, 6(1), 12-20. doi:10.1016/1047-2797(95) 00090-9.

15. Ecob, R., \& Smith, G. D. (1999). Income and health: What is the nature of the relationship? Social Science and Medicine, 48(5), 693-705. doi:10.1016/S0277-9536(98)00385-2.

16. Blumberg, S. J., Olson, L., Frankel, M. R., Osborn, L., Srinath, K. P., \& Giambo, P. (2005). Design and operation of the National Survey of Children's Health, 2003, National Center for Health Statistics. Vital and Health Statistics, Series 1: Programs and Collection Procedures, 43, 1-124.

17. Andersen, R. M. (1995). Revisiting the behavioral model and access to medical care: Does it matter? Journal of Health and Social Behavior, 36(1), 1-10. doi:10.2307/2137284.

18. Halfon, N., Newacheck, P. W., Wood, D. L., \& St Peter, R. F. (1996). Routine emergency department use for sick care by children in the United States. Pediatrics, 98(1), 28-34.

19. Newacheck, P. W., Hughes, D. C., Hung, Y. Y., Wong, S., \& Stoddard, J. J. (2000). The unmet health needs of America's children. Pediatrics, 105(4 Pt 2), 989-997.

20. Avendano, M., Glymour, M. M., Banks, J., \& Mackenbach, J. P. (2009). Health disadvantage in US adults aged 50 to 74 years: A comparison of the health of rich and poor Americans with that of Europeans. American Journal of Public Health, 99(3), 540-548. doi:10.2105/AJPH.2008.139469.

21. Banks, J., Marmot, M., Oldfield, Z., \& Smith, J. P. (2006). Disease and disadvantage in the United States and in England. Journal of the American Medical Association, 295(17), 20372045. doi:10.1001/jama.295.17.2037.

22. Frank, J. W., Cohen, R., Yen, I., Balfour, J., \& Smith, M. (2003). Socioeconomic gradients in health status over 29 years of followup after midlife: The Alameda county study. Social Science and Medicine, 57(12), 2305-2323. doi:10.1016/j.socscimed.2003. 08.003.

23. Kaplan, G. A., Shema, S. J., \& Leite, C. M. (2008). Socioeconomic determinants of psychological well-being: The role of income, income change, and income sources during the course of 29 years. Annals of Epidemiology, 18(7), 531-537. doi: 10.1016/j.annepidem.2008.03.006.

24. Chen, J. T., Krieger, N., Van Den Eeden, S. K., \& Quesenberry, C. P. (2002). Different slopes for different folks: Socioeconomic and racial/ethnic disparities in asthma and hay fever among 173,859 U.S. men and women. Environmental Health Perspectives, $110(2)$, S211-S216.

25. Gehring, U., Pattenden, S., Slachtova, H., et al. (2006). Parental education and children's respiratory and allergic symptoms in the Pollution and the Young (PATY) study. The European Respiratory Journal, 27(1), 95-107. doi:10.1183/09031936.06.00017205.

26. Lewis, S. A., \& Britton, J. R. (1998). Consistent effects of high socioeconomic status and low birth order, and the modifying effect of maternal smoking on the risk of allergic disease during childhood. Respiratory Medicine, 92(10), 1237-1244. doi: 10.1016/S0954-6111(98)90427-9.

27. Strachan, D. P. (2000). Family size, infection and atopy: The first decade of the "hygiene hypothesis". Thorax, 55(1), S2-S10. doi: 10.1136/thorax.55.suppl_1.S2.
28. Bailey, A., Le Couteur, A., Gottesman, I., et al. (1995). Autism as a strongly genetic disorder: Evidence from a British twin study. Psychological Medicine, 25(1), 63-77.

29. Taniai, H., Nishiyama, T., Miyachi, T., Imaeda, M., \& Sumi, S. (2008). Genetic influences on the broad spectrum of autism: Study of proband-ascertained twins. American Journal of Medical Genetics, Part B: Neuropsychiatric Genetics, 147B(6), 844849. doi:10.1002/ajmg.b.30740.

30. Liptak, G. S., Benzoni, L. B., Mruzek, D. W., et al. (2008). Disparities in diagnosis and access to health services for children with autism: Data from the National Survey of Children's Health. Journal of Developmental and Behavioral Pediatrics, 29(3), 152160. doi:10.1097/DBP.0b013e318165c7a0.

31. Mandell, D. S., Ittenbach, R. F., Levy, S. E., \& Pinto-Martin, J. A. (2007). Disparities in diagnoses received prior to a diagnosis of autism spectrum disorder. Journal of Autism and Developmental Disorders, 37(9), 1795-1802. doi:10.1007/s10803-0060314-8.

32. Mandell, D. S., Novak, M. M., \& Zubritsky, C. D. (2005). Factors associated with age of diagnosis among children with autism spectrum disorders. Pediatrics, 116(6), 1480-1486. doi:10.1542/ peds.2005-0185.

33. Zuckerman, B., \& Parker, S. (1995). Preventive pediatrics-new models of providing needed health services. Pediatrics, 95(5), 758-762.

34. Bradford, W. D., Kaste, L. M., \& Nietert, P. J. (2004). Continuity of medical care, health insurance, and nonmedical advice in the first 3 years of life. Medical Care, 42(1), 91-98. doi:10.1097/01. mlr.0000102368.39193.5a.

35. O’Malley, A. S., \& Forrest, C. B. (1996). Continuity of care and delivery of ambulatory services to children in community health clinics. Journal of Community Health, 21(3), 159-173. doi: 10.1007/BF01557996.

36. Schuster, M. A., Duan, N., Regalado, M., \& Klein, D. J. (2000). Anticipatory guidance: What information do parents receive? What information do they want? Archives of Pediatrics and Adolescent Medicine, 154(12), 1191-1198.

37. Halfon, N., Inkelas, M., \& Wood, D. (1995). Nonfinancial barriers to care for children and youth. Annual Review of Public Health, 16, 447-472.

38. Hughes, D. C., \& Ng, S. (2003). Reducing health disparities among children. The Future of Children, 13(1), 153-167. doi: $10.2307 / 1602645$.

39. Currie, J., \& Stabile, M. (2003). Socioeconomic status and health: Why is the relationship stronger for older children? The American Economic Review, 93(5), 1813-1823. doi:10.1257/0002828 03322655563.

40. Lantz, P. M., Lichtenstein, R. L., \& Pollack, H. A. (2007). Health policy approaches to population health: The limits of medicalization. Health Affairs (Project Hope), 26(5), 1253-1257. doi: 10.1377/hlthaff.26.5.1253.

41. Mackenbach, J. P. (2003). An analysis of the role of health care in reducing socioeconomic inequalities in health: The case of the Netherlands. International Journal of Health Services, 33(3), 523-541. doi:10.2190/C12H-NBA4-7QWE-6K3T.

42. Williams, D. R., Costa, M. V., Odunlami, A. O., \& Mohammed, S. A. (2008). Moving upstream: How interventions that address the social determinants of health can improve health and reduce disparities. Journal of Public Health Management and Practice, 14, S8-S17.

43. Halfon, N., DuPlessis, H., \& Inkelas, M. (2007). Transforming the U.S. child health system. Health Affairs (Project Hope), 26(2), 315-330. doi:10.1377/hlthaff.26.2.315.

44. Keating, D. P., \& Hertzman, C. (1999). Developmental health and the wealth of nations: Social, biological, and educational dynamics. New York: The Guilford Press. 
45. Mackenbach, J. P., Stirbu, I., Roskam, A. J., et al. (2008). Socioeconomic inequalities in health in 22 European countries. The New England Journal of Medicine, 358(23), 2468-2481. doi: 10.1056/NEJMsa0707519.

46. Siddiqi, A., Kawachi, I., Berkman, L., Subramanian, S. V., \& Hertzman, C. (2007). Variation of socioeconomic gradients in children's developmental health across advanced Capitalist societies: Analysis of 22 OECD nations. International Journal of Health Services, 37(1), 63-87. doi:10.2190/JU86-457P-7656W4W7.

47. Kunst, A. E., \& Mackenbach, J. P. (1994). The size of mortality differences associated with educational level in nine industrialized countries. American Journal of Public Health, 84(6), 932937. doi:10.2105/AJPH.84.6.932.

48. Alwin, D. F., \& Wray, L. A. (2005). A life-span developmental perspective on social status and health. The Journals of Gerontology, Series B: Psychological Sciences and Social Sciences, 60(2), 7-14.
49. Halfon, N., \& Hochstein, M. (2002). Life course health development: An integrated framework for developing health, policy, and research. The Milbank Quarterly, 80(3), 433-479. doi: 10.1111/1468-0009.00019.

50. Case, A., Fertig, A., \& Paxson, C. (2005). The lasting impact of childhood health and circumstance. Journal of Health Economics, 24(2), 365-389. doi:10.1016/j.jhealeco.2004.09.008.

51. Kim, J., \& Durden, E. (2007). Socioeconomic status and age trajectories of health. Social Science and Medicine, 65(12), 24892502. doi:10.1016/j.socscimed.2007.07.022.

52. Luo, Y., \& Waite, L. J. (2005). The impact of childhood and adult SES on physical, mental, and cognitive well-being in later life. The Journals of Gerontology, Series B: Psychological Sciences and Social Sciences, 60(2), S93-S101.

53. Power, C., Atherton, K., Strachan, D. P., et al. (2007). Life-course influences on health in British adults: Effects of socio-economic position in childhood and adulthood. International Journal of Epidemiology, 36(3), 532-539. doi:10.1093/ije/dyl310. 